\title{
HOSPITAL STAFF READINESS FOR DISASTER MEDICAL SUPPORT
}

\author{
M. Georgieva*, R. Kostadinov, E. Valkanova \\ Department of Epidemiology and Disaster Medicine, Faculty of Public Health, \\ Medical University of Plovdiv, Bulgaria
}

\begin{abstract}
Last decades increase in both disasters' frequency and severity have been recorded globally. Discrepancy between the available and required medical means and capabilities in the area of damage leads to increase of the workload of the hospitals in vicinity. The aim of this study is to analyze hospital staff readiness in case of disaster. In order to achieve the set goal 5-question dichotomous survey was performed between 54 hospital professionals. The questions of our survey are focused on knowledge about hospital Disaster medical support plan and the related medical staff obligations. Results are analyzed and presented by the means of the descriptive, comparative and graphic methods. Over $40 \%$ of the participants self-estimate their knowledge as insufficient about all the surveyed topics. There are only 2 questions, where over 50\% of hospital staff are feeling confident in their knowledge. On the other hand, the comparative analysis reveals statistically significant difference between the declared awareness of hospital disaster medical support plan and related obligations, and lack of knowledge about self-protection, medical information flow and allocated resources for disaster management. The results of the performed analyses highlight the need of intensification of hospital staff medical information exchange on issues related to Disaster medical support plan, disaster medical support activities and resources management.
\end{abstract}

Key words: disasters, disaster medical support, hospitals, disaster medical support plan

\section{INTRODUCTION}

Last decades increase in both disasters' frequency and severity have been recorded globally. (1, 2) More than 800 million casualties and over $\$ 50$ billion severe economic losses have been caused by natural and man-made disasters over the past two decades. (3) The amount of resources required for restoration is increasing. (4) The impact of damaging factors on society (population, infrastructure) and environment leads to consequences that could not been managed by society resources. (5) There is an imbalance between demand and supply of resources. (6) This discrepancy between the available and required medical means and capabilities necessary to eradicate consequences defines the disaster. (7) Throughout the disasters, a relatively large number of casualties needs emergency medical assistance in a very limited timeframe, (1) but the above mentioned

\footnotetext{
*Correspondence to: Mariya Georgieva Georgieva, Department of Epidemiology and Disaster Medicine, Faculty of Public Health, Medical University of Plovdiv, Bulgaria, $e$ mail: maria_g_georg@abv.bg
}

discrepancy is real challenge for disaster medical support managers. A lot of other obstacles like building type and location, increased traffic intensity, further hamper disaster medical support operations execution. These negatively effect on healthcare system affects population health. (7) Life and health of the affected population depend on the availability of prepared in means of knowledge, skills and resources, medical professionals. The hospital staff role is essential for disaster medical support. $(5,8)$ Discrepancy between the available and required medical means and capabilities in the area of damage leads to increase of the workload of the hospitals in vicinity of area of damage. $(1,9,10)$ That requires increased effectiveness of the hospital staff operations, which can be achieved by proper training. The necessity and importance of hospital disaster readiness have also to be noted. (6) All medical staff disaster activities are described in detail as standard operating procedures in the hospital disaster medical support plan. (10) However, "the disaster medical support plan is not equal to disaster readiness."(6) In order to achieve plan effectiveness, the medical staff 
activities, independent and/or coordinated with the search and rescue teams, have to be automated through training. Unfortunately, there is no disaster that occurs in accordance to our plans, therefore surprising and unannounced drills are mandatory for real hospital preparedness assessment and training. Disaster medical support records without any doubt describe that main deficiencies into hospital reactions in case of disaster are related to insufficient medical staff awareness, lack of knowledge about the hospital disaster medical support plan and the related duties. What is more, these are risk factors for development of secondary area of damage within the hospital, $(1,2,6,11)$ thus reducing the hospital disaster resilience.

The aim of this study is to analyze hospital staff readiness in case of disaster.

\section{MATERIALS AND METHODS}

In order to achieve the set goal 5-question dichotomous survey (Table 1) was performed among 54 hospital professionals. The questions are focused on knowledge about hospital disaster medical support plan and the related medical staff duties. Results are analyzed and presented by the means of the descriptive, comparative and graphic methods.

\section{RESULTS AND DISCUSSION}

Answers provided by the participants into the questionnaires are presented into Table 2. It is noteworthy that only around $50 \%$ of respondents consider themselves familiar with the hospital disaster medical support plan. The same unsatisfactory is the level of awareness about related to the disaster medical support plan duties and activities.

The picture is becoming more stressful while analyzing the results obtained for the next 3 questions:

1. Only 43\% ( $\mathrm{n}=23)$ know where the individual protective equipment is stored and from whom they can receive them.
GEORGIEVA M., et al.

2. 57\% $(\mathrm{n}=31)$ are not familiar with the medical information they have to exchange in case of a disaster.

$3.39 \%(\mathrm{n}=21)$ are unaware about the hospital allocated resources of medicines and consumables for disaster management.

These poor results are timely more surprising in comparison with the above $50 \%$ affirmative answers given to the first 2 questions.

All the information about medical information exchange, the allocated resources and protective equipment for disaster management are included in the disaster medical support plan. How you can be familiar with the hospital disaster medical support plan when you are ignorant on what is written in it?

The average results of how healthcare professionals assess their personal knowledge and readiness for surviving and medically supporting disaster related casualties are presented in Figure 1. Obviously, 52\% of respondents consider their knowledge as insufficient. The answers obtained in the survey proves that the majority of hospital medical professionals are unconfident about their knowledge and skills regarding disaster medical support. The results of the research are indicative of the deficiency into the medical staff disaster preparedness both theoretical and practical.

\section{CONCLUSION}

The analyzes performed into the study allow us to conclude that in order to achieve greater effectiveness of disaster medical support materials describing in details the medical professionals' responsibilities have to be created and implemented into practice via individual training.

The results of the performed analyses highlight the need of intensification of hospital staff medical information exchange on issues related to disaster medical support plan, disaster medical support activities and resources management.

Table 1. The questionnaire used in this study

\begin{tabular}{|cl|}
\hline \multicolumn{1}{|c|}{ Knowledge about hospital disaster medical support plan } \\
\hline 1. & Are you familiar with the hospital disaster medical support plan? \\
\hline 2. & Are you familiar with your obligations related to the hospital disaster medical support plan? \\
\hline 3. & $\begin{array}{l}\text { Do you know where the individual protective equipment means are stored and from who you } \\
\text { can receive them in case of a disaster? }\end{array}$ \\
\hline 4. & $\begin{array}{l}\text { Are you familiar with the medical information you have to collect, process and hand over in } \\
\text { case of a disaster? }\end{array}$ \\
\hline 5. & $\begin{array}{l}\text { Do you know if the hospital has allocated resources of medicines and consumables for } \\
\text { disaster management? }\end{array}$ \\
\hline
\end{tabular}


Table 2. Respondents' answers

\begin{tabular}{|l|l|l|}
\hline Question & YES & NO \\
\hline 1 & $32(59 \%)$ & $22(41 \%)$ \\
\hline 2 & $31(57 \%)$ & $23(43 \%)$ \\
\hline 3 & $23(43 \%)$ & $31(57 \%)$ \\
\hline 4 & $23(43 \%)$ & $31(57 \%)$ \\
\hline 5 & $21(39 \%)$ & $33(61 \%)$ \\
\hline
\end{tabular}

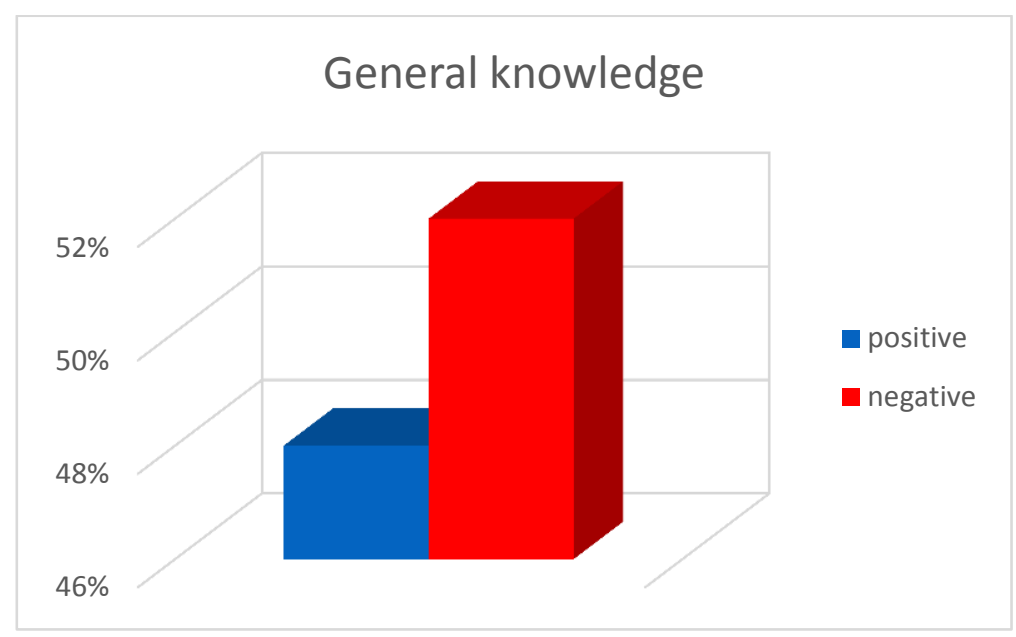

Figure 1. Respondents' general knowledge

\section{REFERENCES}

1. Smith S., Gorski J., Vennelakanti H. C. Disaster preparedness and response: a challenge for hospitals in earthquake-prone countries. Int. J. Emerg. Management, Vol. 7, Nos. 3/4, pp. 209-220, 2010

2. Al-Shaqsi S., Gauld R. et al. Challenges of the New Zealand healthcare disaster preparedness prior to the Canterbury earthquakes: a qualitative analysis. NZMJ, Vol. 126:1371, pp. 9-18, 2013

3. Zarei V. Emergency preparedness of hospitals in Tehran and its relation with crisis management measures. Int. Journal of Med. Research \& Health Sciences, Vol. 5, N. 9S, pp. 471-478, 2016

4. Abdalla S. M. Medical and para-medical staff awareness about disaster management at assiut university hospital. Asian Academy of Management Journal, Vol. 10, N. 3, pp. 67-93, 2012

5. S. P. Salamati Nia, U. Kulatunga. Safety and security of hospitals during natural disasters: challenges of disaster managers. Int. J. of Safety and Security Eng., Vol. 7, No. 2, pp. 234-246, 2017

6. Kaji A. H., Lewis R. J. Hospital Disaster Preparedness in Los Angeles County. Acad.
Emerg. Med. Vol. 13(11), pp. 1198-203, 2006

7. Alexander D. Disaster and Emergency Planning for Preparedness, Response and Recovery. Available on:http://naturalhazardscience.oxfordre.com /view/10.1093/acrefore/9780199389407.00 1.0001/acrefore-9780199389407-e-12

8. Ogedegbe C., Nyirenda T., et al. Health care workers and disaster preparedness: barriers to and facilitators of willingness to respond. Int. J. of Emerg. Medicine, Vol. 5:29, 2012

9. Walczyszyn M., Patel S., et al. Perceptions of hospital medical personnel on disaster preparedness. F1000Research, Vol. 5:1938, 2016

10. Kollek D. Hospital Disaster Readiness: Why Are We Unprepared? Available on: http://www.ceep.ca/publications/HospitalDi sasterReadinessWhyAreWeUnprepared.pdf

11. Hegazy I., Taha M. et al. Assessing the Awareness Regarding Disaster Management Plan among an Interprofessional Team in a University Hospital. Int. J. Med. Med. Sci., Vol. 3(2) pp. 32-39, 2016 